\title{
Modeling and data perspectives on reconstructing Late Pleistocene ice sheets
}

\author{
Pippa L. Whitehouse ${ }^{1}$ and Lev Tarasov ${ }^{2}$ \\ Grenoble, France, 22-24 May 2014
}

\begin{abstract}
The aim of the "Joint model-data workshop for the Late Pleistocene evolution of the Greenland and Antarctic ice sheets" was to bring together scientists from the disciplines of field- and model-based ice-sheet reconstruction to identify outstanding issues in each field, and determine how the different communities could work together towards resolving them. An overarching theme of the workshop was the quantification of uncertainty, associated with both field data and model output.
\end{abstract}

In terrestrial studies of past ice extent (e.g. Fig. 1) it was highlighted that dating continues to be an issue due to a lack of dateable material, the presence of recycled carbon, and the difficulty of interpreting cosmogenic isotope data due to inheritance from multiple glacial cycles. The attribution of landform ages based on weathering characteristics is also difficult because processes can be very different from those observed in temperate regions. Relative sea-level data record the isostatic response to ice-load changes; however, such data are sparse, particularly around Antarctica.

Reviews of offshore information highlighted that many landforms relating to past ice extents are undated and sediment cores are often only acquired from trough regions, where the ice-sheet history may be very different to inter-trough regions. In addition, dating difficulties are compounded by the need to account for marine reservoir effects and interpret the stratigraphy "remotely" using underwater imagery.

In both terrestrial and marine regimes the issue of how to scale up point-based observations, e.g. from individual outcrops to icesheet scale, remains a challenge, although paleo-flow indicators are proving useful for reconstructing regional ice dynamics. The interpretation of radar-detected layers within the ice itself is offering novel constraints on past ice-sheet configurations over large spatial and temporal scales. However, there is little information relating to pre-Last Glacial Maximum ice margins and it remains difficult to quantify rates of ice-sheet growth.

From a modeling point of view discussion focused on how to better represent the forcing factors and boundary conditions governing past ice dynamics. Constraints on past precipitation and air temperature can be obtained from ice cores, but the interpretation of such records relies on having a reliable chronology. It was also noted that ice cores are generally drilled in ice sheet interiors, and hence may not provide reliable forcing conditions for the whole ice sheet. As an example, air and marine temperatures at the margins of ice sheets exert a strong

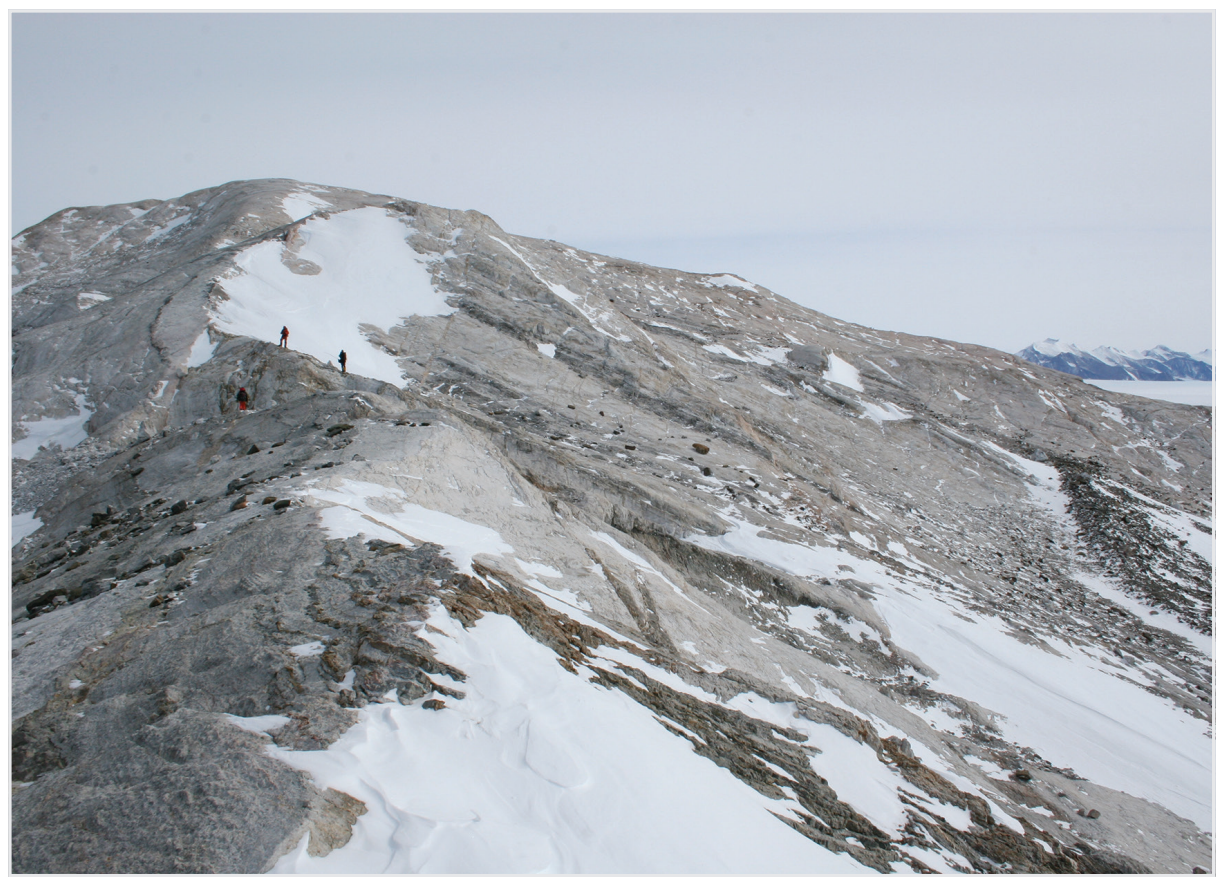
databases - containing both field data and model output - was identified as an important collaborative need. A key outcome of the meeting was an agreement to promote protocols for database standardization among major Quaternary journals.

\section{ACKNOWLEDGEMENTS}

This workshop was supported by the International Association of Cryospheric Sciences, the International Union of Geodesy and Geophysics, the Laboratoire de Glaciologie et Géophysique de l'Environnement, Past Antarctic Ice Sheet Dynamics, and the Scientific Committee on Antarctic Research, and organized by the Meltwater routing and Ocean-Cryosphere-Atmosphere response (MOCA) network.

\section{AFFILIATIONS}

'Department of Geography, Durham University, UK 2Department of Physics and Physical Oceanography, Memorial University of Newfoundland, St John's, Canada

\section{CONTACT}

Pippa L.Whitehouse: pippa.whitehouse@durham.ac.uk

Figure 1: Erratics scattered on the bedrock surface of a nunatak in the Ellsworth Mountains, Antarctica.

Cosmogenic exposure ages on such erratics can determine the timing of ice-sheet thinning. Photo: M. Bentley. 